\title{
BASOPHILIC LEUCOCYTES IN CHILDREN IN HEALTH AND DISEASE
}

\author{
BY \\ ROSS G. MITCHELL \\ From the Department of Child Health, University of St. Andrews, Dundee
}

(RECEIVED FOR PUBLICATION NOVEMBER 5, 1957)

The presence of basophilic leucocytes (basophils)* in human blood was first established by Ehrlich (1891). These cells differ from other polymorphs by their slightly smaller size, by the metachromatic staining reaction of their granules, and by their slower rate of motility (Sabin, 1923). Probably less is known about the basophils than about any of the other formed elements in the blood, mainly because they are very scanty in the peripheral blood and because until 1953 there was no satisfactory method of counting them accurately. Counts based on examination of blood smears are unreliable unless very large numbers of cells are counted and consequently in most studies of the variations of leucocytes in disease the basophils have been ignored or dismissed in a few words as of no significance. In his monograph on mast cells, Michels (1938) gathered most of the information about basophils available at that time and the inaccuracy and contradictions of many of the earlier papers are readily apparent on reading this review, in which the author stigmatized much of the previous literature as 'worthless'. The few standard paediatric textbooks which do more than mention the existence of basophils merely remark on the lack of information available. For example, Nelson's Textbook of Pediatrics (Nelson, 1954) states that 'basophils occur in small numbers in the blood of children. Their function is unknown and they appear to have clinical significance only in that they are consistently elevated in chronic myelogenous leukemia in children'.

Recent evidence that basophils contain heparin (Behrens and Taubert, 1952; Martin and Roka, 1953) and histamine (Graham, Lowry, Wheelwright, Lenz and Parish, 1955; Code and Mitchell, 1957) throws fresh light on the function of these cells, while the introduction of a chamber-counting method by Moore and James (1953) has made it possible to

\footnotetext{
* 'Basophil' should correctly be spelled 'basiphil' since it is derived from the Greek word $\beta a ́ \sigma(s$ (basis) but the spelling 'basophil' has become established in the literature.
}

measure even small changes in the numbers of circulating basophils with considerable accuracy. It therefore seemed worth while to undertake a study of these cells in the blood of children in order to determine more accurately the changes which occur in response to disease. The three diseases chosen for study were lobar pneumonia, acute rheumatism, and anaphylactoid purpura (Schönlein-Henoch syndrome), as examples of common acute diseases of varied aetiology in children.

The basophils were also counted in the blood of 67 healthy children, in order to obtain some indication of the normal variations.

\section{Methods and Procedure}

The method used was essentially that described by Moore and James (1953), except that $0.075 \%$ toluidine blue (B.D.H.) was used instead of $0.05 \%$ as recommended. The stain was adjusted to $p \mathrm{H}$ 7.75 with sodium hydroxide and filtered before the addition of saponin, which was made up as a $30 \%$ solution in $50 \%$ ethyl alcohol. Basophils, eosinophils and total leucocytes were counted simultaneously in the same counting chambers, all the counts being made by the author.

Free-flowing capillary blood obtained by fingerprick was used and all counts were made between 12 noon and 2 p.m., in nearly every case just before a meal. The only exception to this was that the initial counts in acutely ill children were made as soon as possible after admission to hospital, regardless of the time of day. Counts were made daily for the first five days after admission, at one week, and thereafter twice weekly.

The erythrocyte sedimentation rate (E.S.R.) was determined by a modification of Cutler's micromethod, except where otherwise indicated.

Healthy Children. The healthy children had been admitted to hospital for the treatment of some minor anatomical abnormality, in the great majority of 
cases an inguinal hernia, and a smaller group who were admitted to a short-stay children's home for social reasons, usually because the mother was in hospital. There were also a few enuretic children in whom full investigation had revealed no physical cause of the symptom. None of the children had a history of allergic diseases.

Lobar Pneumonia. Cases of pneumonia had to satisfy the following criteria: (a) onset of symptoms within the previous four days; $(b)$ leucocytosis of over 12,000 per c.mm.; (c) pyrexia of at least $100^{\circ} \mathrm{F}$; (d) radiological evidence of pulmonary consolidation.

Eleven cases of pneumonia were studied, and all were treated with penicillin injected intramuscularly; two children (Cases 4 and 5) had a sulphonamide drug in addition. Ten of the children made a rapid and uninterrupted recovery while one seriously ill child (Case 8) did not respond to penicillin but rapidly recovered when treatment was changed to oral tetracycline on the fifth day.

Acute Rheumatism. To be included, cases of acute rheumatism had to satisfy the following criteria, which also fulfil the requirements for the diagnosis of rheumatic fever laid down by Jones (1944): (a) duration of symptoms for one week or less; (b) leucocytosis; (c) pyrexia; (d) migrating polyarthritis; (e) presence of a significant cardiac murmur; $(f)$ E.S.R. above $50 \mathrm{~mm}$. in the first hour. Nine children with acute rheumatism were studied; they were treated with salicylates in a dose of approximately $1 \mathrm{gr}$. per $\mathrm{lb}$. per day, and an initial course of penicillin by intramuscular injection lasting one week.

Anaphylactoid Purpura. Children with anaphylactoid purpura were included in the study if they showed the specific exanthem (Gairdner, 1948), purpura of the characteristic distribution, and one or more swollen, painful joints. No child who had had a previous attack was included. Six children satisfied the criteria (Cases 22 to 27); except where indicated the only treatment given was a course of intramuscular penicillin lasting one week. Because of the interval which usually elapsed before the child was sent into hospital it was not always possible to make the first basophil count at the beginning of the disease, but it was made within a week of onset in five children and within two weeks in the sixth (Case 27). When the first count was made, however, all the children had fresh purpura and acute joint manifestations or acute abdominal pain with tenderness and muscle guarding.

\section{Results}

Healthy Children. Counts of basophils, eosinophils and total leucocytes were made on a single occasion in each of 67 healthy children. There were 46 boys and 21 girls, their ages ranging from 6 months to 12 years. The mean basophil count for the whole group was $45 \cdot 0 \pm 2 \cdot 5$ per c.mm., with a standard deviation of $\pm 20 \cdot 1$ and a range from 13 to 94 per c.mm. The mean count for the boys was $45 \cdot 6 \pm 3 \cdot 1$ (S.D. $\pm 21 \cdot 3$ ) and for the girls $43 \cdot 6 \pm 3 \cdot 5$ (S.D. $\pm 17 \cdot 5$ ). When the children were grouped according to age, the mean counts were as follows:

\begin{tabular}{ccrcc}
$\begin{array}{c}\text { Age } \\
\text { (years) }\end{array}$ & & No. & \multicolumn{2}{c}{$\begin{array}{c}\text { Basophils } \\
\text { per c.mm. }\end{array}$} \\
-1 & $\ldots$ & 7 & $\ldots$ & $44 \cdot 0$ \\
$1-2$ & $\ldots$ & 9 & $\ldots$ & $45 \cdot 3$ \\
$2-3$ & $\ldots$ & 10 & $\ldots$ & $44 \cdot 7$ \\
$3-5$ & $\ldots$ & 13 & $\ldots$ & $46 \cdot 7$ \\
$5-8$ & $\ldots$ & 14 & $\ldots$ & $44 \cdot 4$ \\
$8-12$ & $\ldots$ & 14 & $\ldots$ & $44 \cdot 5$
\end{tabular}

The basophil count thus does not alter significantly throughout childhood.

The mean eosinophil count for the whole group was $245 \cdot 8 \pm 22 \cdot 7$ per c.mm., with a standard deviation of $\pm 185 \cdot 5$, and the mean total leucocyte count was 8,390 per c.mm.

In general the eosinophil count tended to be low when the basophil count was low and high when it was high, but there were many exceptions and the numerical relationship between the two types of cell was not a close one.

Lobar Pneumonia. The results of serial basophil counts in the 11 children with lobar pneumonia are shown in Fig. 1 and Table 1. In all cases the basophil count was low on the first day, none being over 20 per c.mm. Clinical recovery was associated with a rapid rise in the basophil count to reach a maximum during the second week, when no count of less than 50 per c.mm. was recorded. Thereafter the numbers of basophils began to fall; the counts were not continued after the third week because the patients were then discharged. As can be seen from Fig. 1, the curve of the mean eosinophil counts was similar to that of the mean basophil counts, and as would be expected the total leucocyte count rapidly fell to normal. In the severely ill boy (Case 8 ) whose illness did not respond to penicillin, the number of basophils remained low for the first four days but increased rapidly when tetracycline was given, reaching 135 per c.mm. on the 17 th day.

Acute Rheumatism. Of the nine children who fulfilled the diagnostic criteria, eight (Cases 12 to 19) pursued an uncomplicated course to recovery and 
TABLE 1

SERIAL BASOPHIL COUNTS IN 11 CASES OF LOBAR PNEUMONIA

\begin{tabular}{|c|c|c|c|c|c|c|c|c|c|c|c|c|}
\hline Case No. & Age (years) & 1 & 2 & 3 & 4 & 5 & $\underset{7}{\text { Days }}$ & 10 & 14 & 17 & 21 & 24 \\
\hline $\begin{array}{r}1 \\
2 \\
3 \\
4 \\
5 \\
6 \\
7 \\
8 \\
9 \\
10 \\
11\end{array}$ & $\begin{array}{l}7 \\
3 \frac{1}{4} \\
6 \frac{1}{4} \\
7 \\
2 \frac{1}{4} \\
3 \\
2 \frac{1}{2} \\
8 \frac{1}{4} \\
2 \frac{3}{4} \\
5 \\
9\end{array}$ & $\begin{array}{r}16 \\
13 \\
20 \\
19 \\
6 \\
19 \\
19 \\
0 \\
12 \\
12 \\
17\end{array}$ & $\begin{array}{r}25 \\
34 \\
28 \\
31 \\
13 \\
31 \\
25 \\
0 \\
19 \\
16 \\
25\end{array}$ & $\begin{array}{r}37 \\
38 \\
31 \\
25 \\
25 \\
37 \\
45 \\
6 \\
31 \\
31 \\
29\end{array}$ & $\begin{array}{l}34 \\
42 \\
31 \\
25 \\
47 \\
38 \\
41 \\
13 \\
45 \\
53 \\
30\end{array}$ & $\begin{array}{l}\text { (Bas } \\
38 \\
44 \\
43 \\
29 \\
45 \\
46 \\
46 \\
22 \\
42 \\
52 \\
44\end{array}$ & $\begin{array}{c}\text { hils pe } \\
41 \\
46 \\
75 \\
38 \\
72 \\
56 \\
72 \\
47 \\
49 \\
87 \\
40\end{array}$ & $\begin{array}{c}\text { c. mm.) } \\
66 \\
78 \\
100 \\
55 \\
63 \\
74 \\
53 \\
66 \\
91 \\
91 \\
63\end{array}$ & $\begin{array}{r}104 \\
70 \\
63 \\
58 \\
61 \\
56 \\
56 \\
110 \\
116 \\
69 \\
79\end{array}$ & $\begin{array}{r}78 \\
63 \\
53 \\
64 \\
\\
\\
135 \\
52 \\
66 \\
70\end{array}$ & 103 & 55 \\
\hline Mean & & 14 & 22 & 30 & 36 & 41 & 57 & 73 & 77 & 73 & & \\
\hline
\end{tabular}

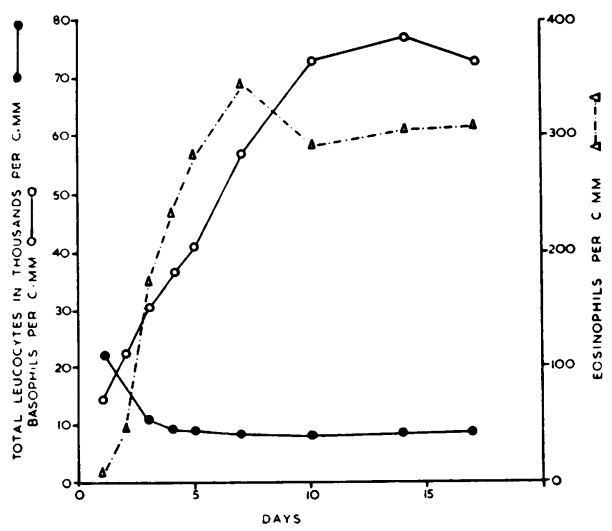

FIG. 1.-Mean basophil, eosinophil and total leucocyte counts in 11 cases of lobar pneumonia.

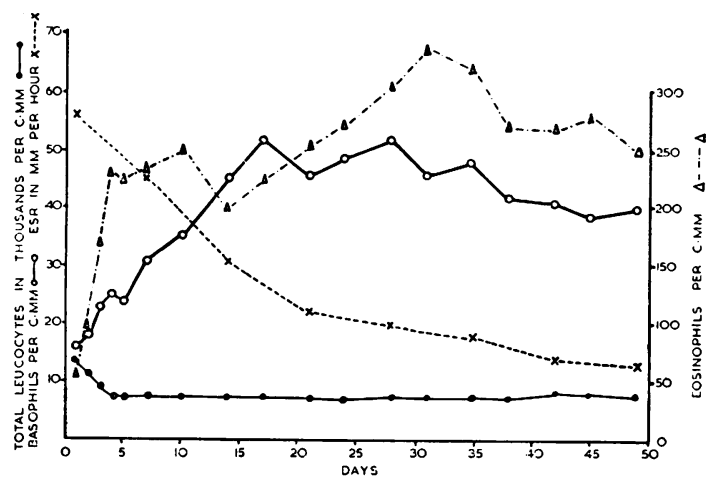

Fig. 2.-Mean basophil, eosinophil and total leucocyte counts and mean erythrocyte sedimentation rates in eight cases of acute rheumatism.

TABLE 2

SERIAL BASOPHIL COUNTS IN EIGHT CASES OF ACUTE RHEUMATISM

\begin{tabular}{|c|c|c|c|c|c|c|c|c|c|c|c|c|c|c|c|c|c|c|c|}
\hline $\begin{array}{c}\text { Case } \\
\text { No. }\end{array}$ & $\begin{array}{c}\text { Age } \\
\text { (years) }\end{array}$ & 1 & 2 & 3 & 4 & 5 & 7 & 10 & 14 & ${ }_{17}$ & $\begin{array}{l}\text { Days } \\
21\end{array}$ & 24 & 28 & 31 & 35 & 38 & 42 & 45 & 49 \\
\hline $\begin{array}{l}12 \\
13 \\
14 \\
15 \\
16 \\
17 \\
18 \\
19\end{array}$ & $\begin{array}{c}12 \\
10 \\
7 \frac{1}{2} \\
11 \frac{1}{2} \\
10 \\
7 \\
11 \\
10\end{array}$ & $\begin{array}{c}1 \\
6 \\
30 \\
29 \\
3 \\
20 \\
16 \\
19\end{array}$ & $\begin{array}{c}9 \\
13 \\
22 \\
25 \\
6 \\
17 \\
22 \\
27\end{array}$ & $\begin{array}{c}9 \\
16 \\
27 \\
31 \\
9 \\
13 \\
44 \\
31\end{array}$ & $\begin{array}{l}19 \\
17 \\
28 \\
34 \\
13 \\
18 \\
44 \\
25\end{array}$ & $\begin{array}{l}25 \\
13 \\
38 \\
25 \\
19 \\
13 \\
41 \\
19\end{array}$ & $\begin{array}{l}31 \\
13 \\
37 \\
29 \\
25 \\
20 \\
45 \\
44\end{array}$ & $\begin{array}{l}38 \\
19 \\
28 \\
28 \\
28 \\
48 \\
36 \\
54\end{array}$ & $\begin{array}{l}\text { (Bas } \\
42 \\
27 \\
28 \\
47 \\
36 \\
63 \\
59 \\
55\end{array}$ & $\begin{array}{c}\text { phils } \\
47 \\
29 \\
42 \\
55 \\
38 \\
50 \\
70 \\
81\end{array}$ & $\begin{array}{r}\text { per c. } \\
32 \\
22 \\
49 \\
48 \\
31 \\
39 \\
63 \\
87\end{array}$ & $\begin{array}{l}\text { m.) } \\
30 \\
31 \\
56 \\
28 \\
39 \\
71 \\
86\end{array}$ & $\begin{array}{l}35 \\
34 \\
59 \\
60 \\
35 \\
45 \\
61 \\
90\end{array}$ & $\begin{array}{l}25 \\
30 \\
41 \\
39 \\
37 \\
64 \\
83\end{array}$ & $\begin{array}{l}28 \\
22 \\
63 \\
50 \\
44 \\
42 \\
53 \\
85\end{array}$ & $\begin{array}{l}29 \\
20 \\
52 \\
38 \\
44 \\
31 \\
42 \\
82\end{array}$ & $\begin{array}{l}30 \\
19 \\
48 \\
34 \\
41 \\
29 \\
42 \\
87\end{array}$ & $\begin{array}{l}\overline{21} \\
50 \\
42 \\
29 \\
25 \\
39 \\
69\end{array}$ & $\begin{array}{l}28 \\
19 \\
56 \\
37 \\
31 \\
33 \\
41 \\
73\end{array}$ \\
\hline Mean & & 16 & 18 & 23 & 25 & 24 & 31 & 35 & 45 & 52 & 46 & 49 & 52 & 46 & 48 & 42 & 41 & 39 & 40 \\
\hline
\end{tabular}

the changes in numbers of basophils are recorded in Fig. 2 and Table 2 . As in the cases with pneumonia, the initial count in every case was low, none being above 30 per c.mm. In most cases the count remained low during the first week, rose gradually to reach a maximum in the third, fourth or fifth week, and thereafter fell slightly to a more or less stationary level. Counts were not continued beyond the seventh week of the illness as the children were usually sent home or transferred to a convalescent home on recovery.

The E.S.R. in all cases diminished steadily as recovery proceeded, being below $15 \mathrm{~mm}$. per hour in six of the eight cases by the seventh week, and reaching this level soon afterwards in the other two. During the initial period of recovery (Figs 2 and 3), when the basophil count was rising to a maximum level, there was an inverse relationship between the 


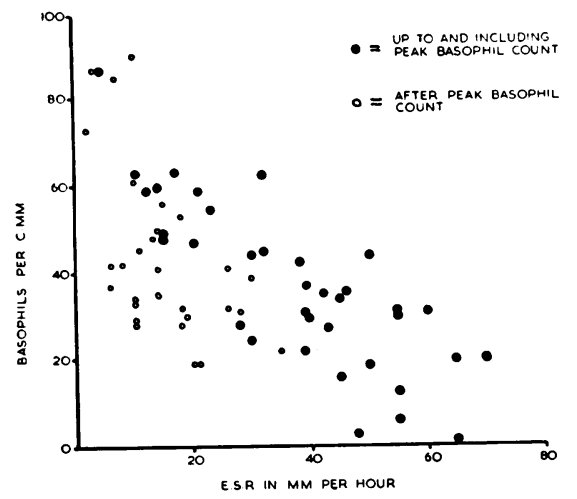

Fig. 3.-The relationship between the basophil count and the erythrocyte sedimentation rate in eight cases of acute rheumatism.

basophil count and the E.S.R. but this relationship ceased as the basophil count began to fall.

The ninth child with acute rheumatism was a boy of 9 years old who had a relapse during his illness and is therefore considered separately (Fig. 4, Case 20).

The basophil count was 25 per c.mm. on admission six days after the onset of symptoms. The pyrexia, leucocytosis and joint pains quickly subsided and after a few days the basophil count began to rise steadily, reaching 81 per c.mm. on the 17 th day. During the same period the E.S.R. was gradually falling. At the end of the fourth week in hospital, however, there was a sudden recurrence of joint pains and pyrexia; the basophil count fell to 16 per c.mm. and the E.S.R. increased again. Salicylate dosage was increased, and the symptoms disappeared; the basophil count again began to rise, reaching 63 per c.mm. before levelling off at 50 per c.mm. Concurrently the E.S.R. fell to normal and the child thereafter made an uninterrupted recovery.

One further child with acute rheumatism who had no polyarthritis, and therefore did not fulfil the criteria, was nevertheless included in the study because she had severe carditis, subcutaneous nodules and a previous history of rheumatism so that the diagnosis could not be in doubt.

She was a girl of 11 years (Fig. 4, Case 21) who had had an acute attack of rheumatism two years previously from which she had made a good recovery. Five days before the first basophil count, she vomited and complained of abdominal pain. Pyrexia developed and on admission she was seriously ill with slight cyanosis, tachycardia, leucocytosis of 19,000 per c.mm., and an E.S.R. of $145 \mathrm{~mm}$. in the first hour (Westergren). Subcutaneous nodules were palpable over the occipital region. Systolic and diastolic murmurs were audible at the heart apex and a radiograph of the chest showed considerable cardiac enlargement. The basophil count was 19 per c.mm. Treatment with salicylates and antibiotics resulted in some improvement; the E.S.R. after
10 days had fallen to $100 \mathrm{~mm}$. per hour and the basophil count had risen to 55 per c.mm. During the next 14 days, however, the child's condition deteriorated, the apex beat moved out into the axilla, the E.S.R. rose again to $121 \mathrm{~mm}$. per hour and the basophil count fell to 28 per c.mm. In view of this deterioration, treatment with cortisone was started; this resulted in disappearance of basophils from the peripheral blood and a fall in the E.S.R. to $10 \mathrm{~mm}$. per hour, and coincided with clinical improvement. Two weeks after starting cortisone, however, she developed acute pharyngitis; the basophil count rose to 48 per c.mm. and the E.S.R. to $25 \mathrm{~mm}$. per hour. With recovery, the basophil count again fell to a very low level, and the E.S.R. returned to normal. The dose of cortisone was gradually reduced, and when it was only $50 \mathrm{mg}$. per day, the basophil count began to rise, and the curve thereafter showed the gradual rise and fall with levelling off between 30 and 40 cells per c.mm., which has been demonstrated in recovery

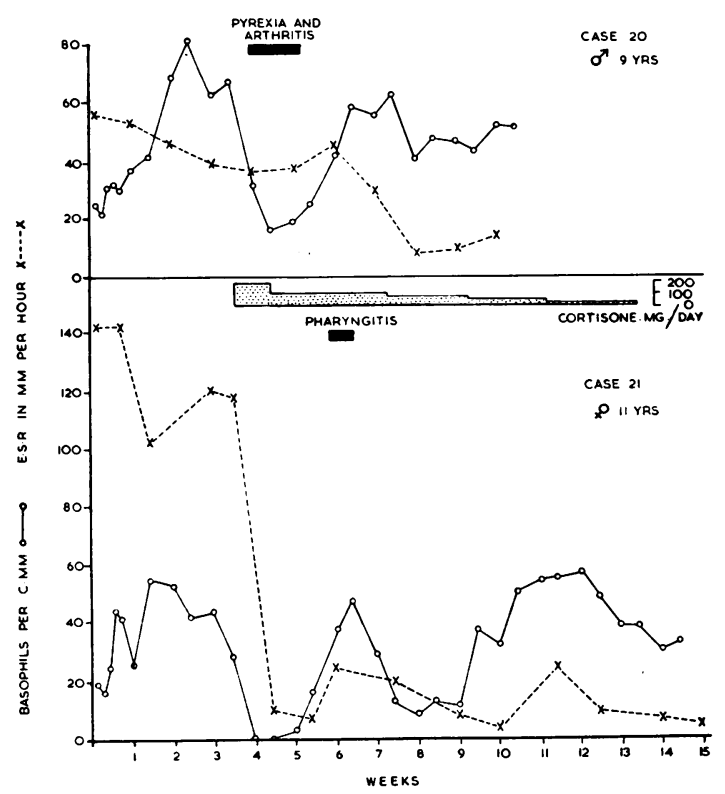

FIG. 4.-Serial basophil counts and erythrocyte sedimentation rates in two cases of acute rheumatism with complications.

from uncomplicated acute rheumatism. On reducing the dose of cortisone the E.S.R. showed a slight rise but quickly fell again to normal, and the child made a steady and uneventful recovery.

This case therefore illustrates a reversal of the usual inverse relationship between the basophil count and the E.S.R. as a result of the action of cortisone in reducing the E.S.R. and lowering the basophil count.

Anaphylactoid Purpura. Because of the variable course of the disease, the six children with anaphy- 


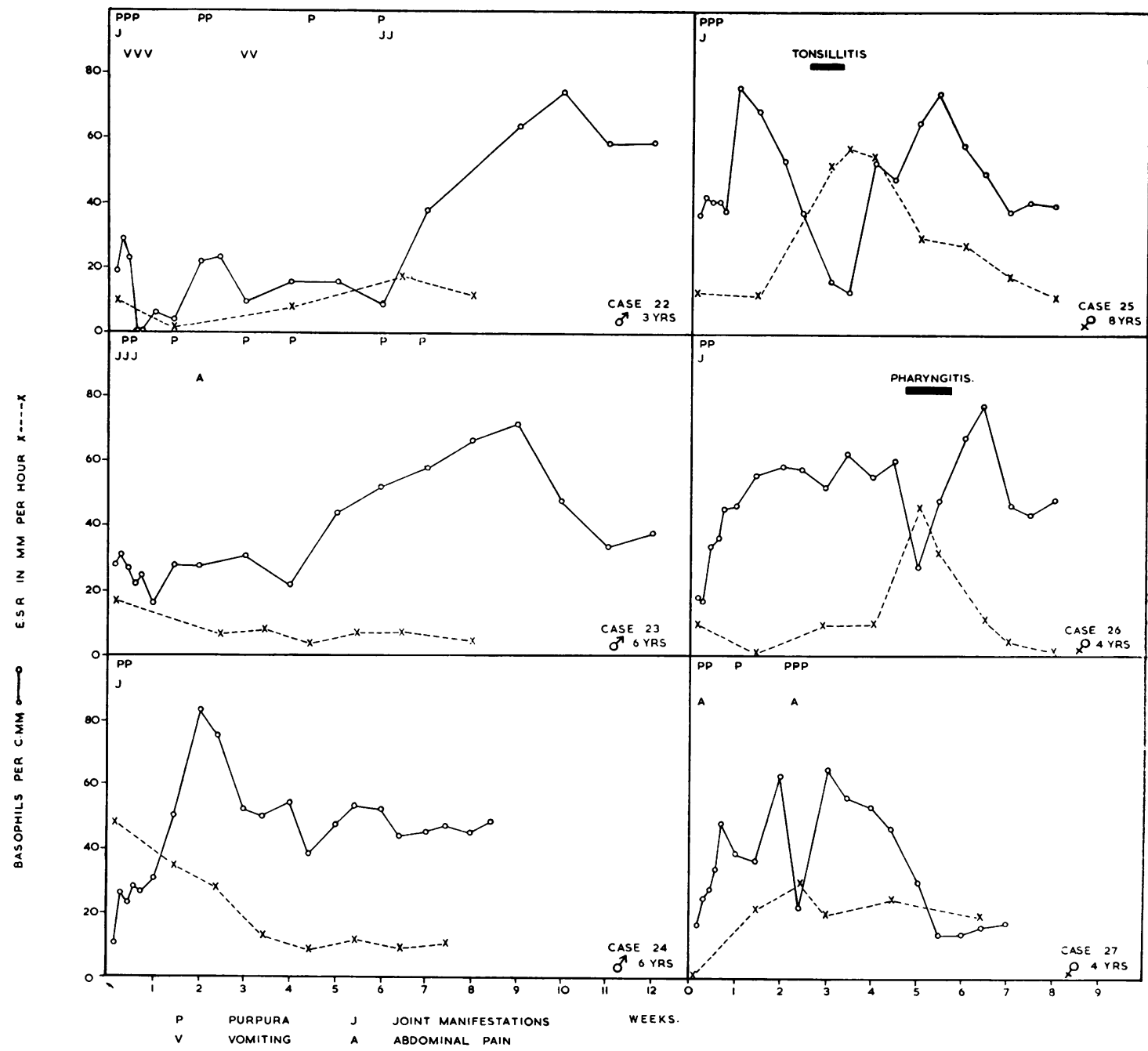

FIG. 5.-Serial basophil counts and erythrocyte sedimentation rates in six cases of anaphylactoid purpura.

lactoid purpura could not be treated as a single group for analysis of the results and the data for each child are therefore presented separately (Fig. 5).

In Case 22, the child was severely ill with vomiting and haematemesis, and fresh purpura continued to appear during the first six weeks. The basophil count remained low during this period, falling even lower during episodes of acute vomiting, and during a recrudescence of joint symptoms in the sixth week. With recovery the number of basophils increased steadily to a maximum count of 75 per c.mm. and then decreased a little and remained fairly stationary. Case 23 showed a similar series of events although the child was not so ill and recovery began about the fifth week. In spite of an uninterrupted clinical recovery this boy continued to have occasional slight purpura without any effect on the basophil count, which rose steadily to a maximum of 72 per c.mm. and then levelled off. In both Cases 22 and 23 the E.S.R. was low throughout the illness.

In Case 24 recovery was rapid and uninterrupted, with no further purpura or arthritis after the first few days. The basophil count rose rapidly from 11 per c.mm. on the day of admission to 83 per c.mm. at the end of two weeks and thereafter fell to about 45 per c.mm. The E.S.R. was high initially, possibly indicating a mild respiratory infection, and fell steadily as recovery progressed. Cases 25, 26 and 27 were each characterized by initial recovery, followed by a relapse or complication, succeeded again by recovery. In case 25 there were no 
further manifestations of the disease after the first few days and the basophil count rose quickly to 76 per c.mm. During the third week it fell rather rapidly and acute tonsillitis developed with pyrexia and an elevated E.S.R. Treatment with penicillin resulted in subsidence of the fever and inflammation, followed by a fall in the E.S.R. and $a$ rise in the basophil count to reach 75 per c.mm. once again. Thereafter the count fell gradually to level off at about 40 per c.mm. Case 26 showed a similar course of events with an initial rise of the basophil count to a level of about 60 per c.mm., and a rapid drop to 28 per c.mm. in the fifth week, coincident with an acute attack of pharyngitis associated with an elevated E.S.R. With recovery from the acute infection, the E.S.R. fell and the basophil count rose to a maximum of 78 per c.mm. before levelling off between 45 and 50 per c.mm.

In Case 27 there was abdominal pain with fresh purpura on admission, when the basophil count was found to be 17 per c.mm. After two days the symptoms subsided and the basophil count rose to 63 per c.mm. at the end of the second week. During the third week there was a fresh outbreak of purpura with further abdominal pain, and the basophil count fell sharply to 22 per c.mm. Thereafter recovery was uninterrupted, the basophil count rose again to 65 per c.mm. and then fell gradually to a level of about 15 per c.mm.

In spite of the variable course pursued in this disease, therefore, there is a pattern in the basophil response. The count is low in the acute stage, and rises during recovery. A relapse or an intercurrent infection is usually associated with an abrupt fall in the numbers of circulating basophils, which may be the first indication of such a setback.

In anaphylactoid purpura, the occurrence of purpura cannot always be correlated with the clinical condition, and fresh crops of purpura may appear from time to time long after apparent recovery. Similarly the basophil count could not be related to the occurrence of purpura, but reflected rather the general clinical state. It was particularly noticeable that an acute episode of haematemesis with shock could result in the immediate disappearance of circulating basophils, as in Case 22; whereas the number of basophils might steadily increase in spite of recurring purpura, as in Case 23. Only in Case 27 did the recurrence of purpura appear to be associated with an abrupt fall in the basophil count, but there was abdominal pain as well, indicating a more severe disturbance than purpura alone.

In general the eosinophil counts followed the trend of the basophil counts, in so far as the numbers of eosinophils diminished during episodes of acute illness and tended to increase in the recovery phase. The counts were, however, much more variable and sudden and unaccountable fluctuations often took place without coincident changes in the basophil count or the clinical state.

\section{Discussion}

Basophil Counts in Healthy Children. The difficulty of selecting normal children for leucocyte counts has been pointed out by Sturgis and Bethell (1943). Relatively mild infections, such as are common among apparently healthy school children, may cause fluctuations in the leucocyte count, while increased eosinophil and basophil counts have been reported in chronic tonsillar enlargement and chronic sinusitis respectively (Bunting, 1914; Rud, 1947). It was therefore decided to study healthy children in hospital rather than in the schools or at home, because a thorough clinical examination could be made which would ensure the absence of minor infections. For this reason the number of healthy children is small but may nevertheless present a more accurate standard of health than a cross-section of the school population. The preponderance of boys is due to the greater frequency of inguinal hernia in boys than in girls.

The numbers of basophils in the peripheral blood of these healthy children are similar to those found in the blood of adults by the method of Moore and James (1953). Thus the mean count of $45 \cdot 0 \pm 2 \cdot 5$ per c.mm. does not differ significantly from the mean counts of 46.7 per c.mm. found in 36 men by Moore and James, 41.0 per c.mm. in 30 men and women by Angeli, Tedeschi and Cavazzuti (1954), and $44 \cdot 8 \pm 2 \cdot 4$ per c.mm. in 96 men and women by Rorsman (1957a), while the range from 13 to 94 per c.mm. is similar to the ranges of 11 to 107 recorded by Moore and James and of 9.3 to 112.5 recorded by Angeli and his colleagues. After the characteristic rise and fall in the basophil count in the immediate newborn period (Mitchell, 1955) the count remains at the same level throughout childhood, an observation which confirms the work of Kato (1935). Neither Angeli and his colleagues nor Rorsman found significant sex differences in their series of basophil counts and similarly in the present study no difference between the counts in boys and girls was found. Although the number of children is too small to fix the extreme limits of normal, basophil counts below 10 per c.mm. or above 110 per c.mm. should be regarded as probably abnormal, although for any one individual the limits of normal may be very much narrower. It is apparent that the criteria suggested by Alder (1923), namely, that an increase or decrease of more than 15 cells from a mean value of 35 cells per c.mm. should be regarded as pathological, are far too limited.

Basophil Counts in Disease. The ill children to be studied were carefully selected in order to exclude 
those who were only mildly ill or in whom the diagnosis was in doubt. Thus all the children included were moderately to severely ill and presented a 'textbook picture' of the disease concerned. This was considered to be important in determining the characteristic changes in the basophil count for each disease.

The results indicate that in the three acute diseases studied, the circulating basophils are scanty or absent during the acute phase, increase in number during recovery and are plentiful during the immediate convalescent phase of the illness. Similar changes occur in the numbers of eosinophils, a pattern of response to acute infection which is well established (Wolman, 1951; Weiner and Morkovin, 1952). With full clinical recovery the numbers of basophils return to normal levels; counts have not been continued long enough to determine whether further changes occur during the later stages of convalescence.

Basopenia. The finding of low basophil counts in the acute stages of disease is in accord with some of the earlier reports based on counts of basophils made from blood smears. Thus Arneth (1920) stated that basophils disappeared almost completely from the peripheral blood in influenza and Benjamin and Ward (1932) reported that, although individual counts were inaccurate by their method, there was generally a fall in the number of basophils during the febrile phase of measles, with a rise during convalescence amounting to basophilia during the second week. Whitby and Britton (1953) state that basophils may disappear altogether in acute infections. On the other hand Dible's textbook of pathology (1950) states that 'the proportion and number of basophil leucocytes in the blood are practically never affected by disease, if we except myeloid leukaemia and a slight increase in polycythaemia vera'.

There have been few reports based on accurate counting methods. Mallek (1955) and Labendzinski (1956) found low counts in some acute infectious diseases such as typhoid fever and bacillary dysentery, with a rise during recovery. Their technique involved the haemolysis of red cells and staining of basophils in a thick drop of blood, and was therefore an improvement on the older methods, but still lacked the precision of a counting chamber method. Rorsman (1957a), using a modification of the method of Moore and James (1953), found a mean basophil count of only $8 \cdot 1 \pm 2 \cdot 7$ per c.mm. in 22 cases of urticaria; no such basopenia was found in cases of asthma (Rorsman, 1957b).

Low basophil counts in the present series were generally accompanied by eosinopenia, a characteristic phenomenon of stress. It seems reasonable therefore to attribute the diminution in the number of basophils to the stress of the acute disease, since it is an apparently non-specific reaction common to several diseases of varying aetiology. On this view, it might be expected that other forms of stress would also cause basopenia. Camerada and Leo (1955) have shown experimentally that thyroxin causes a decrease in the numbers of basophils as well as of eosinophils, although it must be said that these authors attributed the effect to a specific action of thyroxin. Fig. 6 shows the results of serial basophil counts on a boy of 10 years with hyperthyroidism and a girl of 20 months with hypothyroidism. The

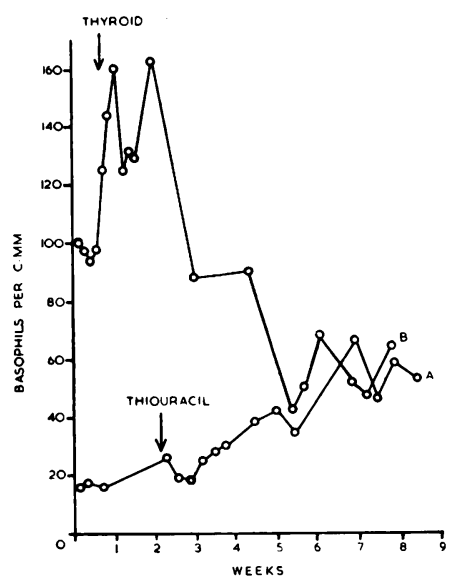

FIG. 6.-Serial basophil counts in (A) a boy with hyperthyroidism treated with thiouracil and (B) a girl with hypothyroidism treated with thyroid extract. basophil count was low in the acutely thyrotoxic state and rose to normal levels on treatment with thiouracil, whereas the basophil count was abnormally high in the cretin, and fell to normal levels after treatment with thyroid was started, with the usual delay of 10 days or so in the response to this hormone. These illustrative cases lend support to the view that the low basophil counts observed in acute disease are the result of nonspecific stress. If such is the case cortisone should cause a disappearance of the basophils from the circulating blood stream, as it does with eosinophils, and this effect has in fact been demonstrated (Code, Mitchell and Kennedy, 1954). It might be argued that the very low basophil counts found in urticaria by Rorsman (1957a) were due to stress, but here the situation is rather different because urticaria is common to a heterogeneous collection of conditions in many of which there is evidence of disordered histamine metabolism (Rose, 1941; Adam, Hunter and Kinnear, 1950). Rorsman's patients had no general systemic disturbance so that the very low counts observed are more likely to have been peculiar to urticaria and not the result of a nonspecific stimulus.

Basophilia. The present work indicates that there 
are increased numbers of circulating basophils during the phase of recovery from an acute disease. Increases in the numbers of basophils are more readily observed by differential counts from blood smears than decreases, and therefore although earlier reports on the incidence of low basophil counts were often uncertain and conflicting, there is a larger and to some extent more reliable collection of evidence that the basophil count may be increased in certain diseases. Thus it is established that there may be very considerable numbers of circulating basophils in leukaemia and in polycythaemia (Ehrlich, 1891; Alder, 1923; Doan and Reinhart, 1941). Although extremely high counts have been recorded in leukaemia, even as high as 163,000 basophils per c.mm. (Joachim, 1906), the highest count so far recorded by the present writer was 237 basophils per c.mm. in a boy of 3 years with acute leukaemia, who had 400,000 leucocytes and 419 eosinophils per c.mm. When the total leucocyte count fell to 30,400 per c.mm. one week after starting treatment with mercaptopurine, the basophils fell to 17 per c.mm. and the eosinophils to 25 per c.mm., while at two weeks the leucocyte count was 4,800 per c.mm. the basophils were 9 per c.mm. and the eosinophils had disappeared completely. This suggests that mercaptopurine may have a greater effect than irradiation on the basophils in leukaemia, since there is evidence that these cells are resistant to radioactive agents (Doan and Reinhart, 1941; Johansen, 1955), with the possible exception of radioactive phosphorus (Turchini and Kein, 1955).

Apart from these diseases of the blood-forming organs, an increase in the number of circulating basophils has been reported in other blood diseases, such as chronic haemolytic anaemia and chlorosis (Alder, 1923), and in diseases of the skin (Canon, 1892; Klausner and Kreibich, 1913). Bunting (1914) reported that the basophils are increased in early Hodgkin's disease, but thought that this might be due to chronic sinusitis, which according to this author is constantly associated with an increased number of basophils. Graham (1920) reported increased numbers of basophils in a patient infected with hookworms. Nevertheless, as recently as 1951, Muir's Textbook of Pathology observed that 'there is no condition known which regularly calls forth a basophil leucocytosis'.

Bigart (1902) and Rubinato (1907) reported that in cirrhosis of the liver there were greatly increased numbers of circulating basophils, amounting to as much as $20.6 \%$ of the total leucocyte count in one case, an observation of some interest since high levels of blood histamine have recently been recorded in this disease (Mitchell, Butt and Code, 1954).
As with the initial basopenia, the basophilia during recovery from acute disease cannot at present be related to any function of the basophils, but is probably a non-specific response to the earlier stress.

Clinical Value of Basophil Counts. The eosinophil count is of some use as a guide to progress in an acute infection (Hain, 1951; Whitby and Britton, 1953), and the greater consistency of the basophil count suggests that it might be of even greater value. Moreover, the demonstrated relationship between the basophil count and the E.S.R. indicates a possible use for the basophil count in the prognosis of acute rheumatism, since a steady increase in the number of circulating basophils has the same significance as a steadily falling E.S.R. Unfortunately the limiting factor is the wide range of normal values, compared with the small range of normal for the E.S.R. The basophil count is remarkably constant in the healthy individual but the normal level is not usually known when a patient is seen in the acutely ill stage. Occasionally the basophil count performed daily has proved of value, when a sudden fall in the number of basophils has been the first indication of a relapse, preceding clinical manifestations by a day or more. Nevertheless increasing experience of basophil counts in a variety of clinical conditions indicates that not enough is known about the factors which may influence the count to permit its use as a reliable clinical test at present.

Functions of the Basophil. In the early years of this century there was much discussion on the relationship of the basophils (mast cells of the blood) to the mast cells of the tissues, but by the late thirties enough information had accumulated to enable Michels (1938) to state that 'in mammals the two types have nothing in common save the basophilic metachromatic staining granules'. This statement must be modified today, since the tissue mast cells, like the basophils, contain both heparin and histamine (Jorpes, 1946; Riley and West, 1953). Nevertheless, the balance of evidence still favours the view that the two types of cell are distinct.

At various times the basophils have been regarded as degenerating lymphocytes, as unripe eosinophils, and even as 'a vestigial remain analogous with the appendix' (Phillips, 1953), but they are now generally accepted as mature granulocytes fully equivalent to the eosinophils and neutrophils (Michels, 1938). There may, however, be a functional relationship between basophils and eosinophils, since they have certain properties in common such as their response to stress or to cortisone (Code et al., 1954; Hamerston, Elveback, Halberg and Gully, 1956). Moreover, there is evidence that while basophils are the 
main reservoir of histamine in the blood, the eosinophils also sometimes carry histamine, providing additional histamine-carrying capacity which is readily available when the occasion arises (Code and Mitchell, 1957).

It seems reasonable to assume that the content of such potent substances as heparin and histamine bears some relationship to the function of the basophil, although there may be other, possibly more fundamental, activities. Tötterman (1948) searched for evidence of an increased tendency to haemorrhage when increased numbers of basophils were present in the peripheral blood, but was unable to demonstrate that such basophilia predisposed to bleeding. This is perhaps not surprising, since Angeli and his colleagues (1955) showed experimentally that the intravenous injection of heparin caused an increase in the number of circulating basophils, and that the period of maximum augmentation of the basophil count coincided with the most rapid diminution in anti-coagulant activity of the injected heparin, an effect which they attributed to a specific regulatory action of the basophils. Wintrobe (1951) considered that basophils might function in inflammation by delivering anticoagulants to facilitate absorption or to prevent clotting of blood and lymph in the obstructed tissue. The chemical studies of Turchini and Kien (1955) led them to believe that in the presence of disease the synthesis of heparin in the basophils is disturbed so that precursor substances are liberated which are necessary for the elimination of toxic products.

As far as histamine is concerned, Graham and her colleagues (1955) suggested that the basophils may be a source of a limited amount of the amine which is immediately available wherever needed to tide over the period before the arrival of more adequate supplies from the tissue mast cells. It is possible, on the other hand, that the basophils are simply a safe means of transporting a potentially toxic substance pending its destruction or excretion.

It is apparent that in spite of recent progress we are still a long way from answering what Riley (1954) has called the 'riddle of the mast cells', and the answer is unlikely to be found until the larger problems of the physiological significance of heparin and histamine in the body have been solved.

\section{Summary}

The circulating basophils have been counted in 67 healthy children and in 27 acutely ill children throughout the course of their illness.

The counts in healthy children were not significantly different from those found in adults by other authors, and the mean count did not vary significantly throughout childhood.

In the three acute diseases studied, lobar pneumonia, acute rheumatism, and anaphylactoid purpura, the number of circulating basophils was always low in the acute stage and high during the stage of recovery. These are regarded as nonspecific changes in response to the stress of the acute disease.

Serial basophil counts give some indication of the progress of the disease but are not sufficiently reliable to be of practical clinical use at present.

Possible functions of the basophils are discussed.

I am grateful to Professor J. L. Henderson for his encouragement and criticism.

\section{REFERENCES}

Adam, H. M., Hunter, R. B. and Kinnear, T. W. G. (1950), Ouart. J. exp. Physiol., 36, 49.

Alder, A. (1923). Folia haemat. teil l. Arch. (Lpz.), 28, 249.

Angeli, G., Tedeschi, G. and Cavazzuti, F. (1954). Prog. med. (Napoli), 10, 742 .

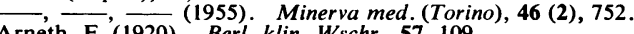

(1920). Berl. klin. Wschr., 57, 109.

Behrens, M. and Taubert, M. (1952). Klin.Wschr., 30, 76.

Benjamin, B. and Ward, S. M. (1932). Amer. J. Dis. Child., 44, 921:

Bigart, M. (1902). C.R. Soc. Biol. (Paris), 54, 1529.

Bunting, C. H. (1914). Johns Hopk. Hosp. Bull., 25, 173.

Camerada, P. and Leo, P. (1955). Rass. med. Sarda, n.s. 6, 163.

Canon, P. (1892). Disch. med. Wschr., 18, 206

Code, C. F. and Mitchell, R. G. (1957). J. Physiol. (Lond.), 136, 449. - and Kennedy, J. C. (1954). Proc. Mayo Clin., 29, 200.

Dible, J. H. (1950). Dible and Davie's Pathology, 3rd ed. 'London.

Doan, C. A. and Reinhart, H. L. (1941). Amer. J. clin. Path., 11, 1.

Ehrlich, P. (1891). Farbenanalytische Untersuchungen zur Histologie und Klinik des Blutes. Berlin.

Gairdner, D. (1948). Quart. J. Med., n.s. 17, 95.

Graham, G. S. (1920). J. exp. Med., 31, 209.

Graham, H. T., Lowry, O. H., Wheelwright, F., Lenz, M. A. and Parish, H. H. Jr. (1955). Blood, 10, 467.

Hain, K. (1951) Pediatrics, 7, 408.

Hamerston, O., Elveback, L., Halberg, F. and Gully, R. J. (1956). J. appl. Physiol., 9, 205.

Joachim, G. (1906). Disch. Arch. klin. Med., 87, 437

Johansen, C. (1955). Nord. Med., 53, 212.

Jones, T. D. (1944). J. Amer. med. Ass., 126, 481.

Jorpes, J. E. (1946). Heparin in the Treatment of Thrombosis, 2nd ed. London.

Kato, K. (1935). J. Pediat., 7, 7.

Klausner, E. and Kreibich, C. (1913). Folia haemat. teil l. Arch. (Lpz.), 15, 347.

Labendzinski, F. (1956). Sang, 27, 432

Mallek, D. (1955). Pol. Tyg. lek., 10, 1400.

Martin, H. and Roka, L. (1953). Acta haemat. (Basel), 10, 26.

Michels, N. A. (1938). In Handbook of Hematology, ed. H. Downey,

London.
Mitchell, R.G.(1955). Arch. Dis. Childh., 30, 130.

, Butt, H. R. and Code, C. F. (1954). J. clin. Invest., 33, 1199.

Moore, J. E. III and James, G. W. III (1953). Proc. Soc, exp. Biol. (N.Y.), 82, 601 .

Muir, R. (1951). Muir's Textbook of Pathology. Revised by D. F. Cappell, 6th ed. London.

Nelson, W E (1954). Textbook of Pediatrics, 6th ed. Philadelphia.

Phillips, W. (1953). In Medicine, ed. H. G. Garland and W. Phillips, London.

Riley, J. F. (1954). Lancet, 1, 841.

and West, G. B. (1953). J. Physiol. (Lond.), 120, 528.

Rorsman, H. (1957a). Acta derm.-venereol. (Stockh.), 37, 121.

- (1957b). Personal communication.

Rose, B. (1941). J. Allergy, 12, 327.

Rubinato, J. (1907). Folia. haemat. (Lpz.), 4, Suppl. p. 198

Rubinato, J. (1907). Folia. haemat. (Lpz.), 4, Suppt.

Rud, F. (1947). Acta psychiat. (Kbh.), Suppl. 40.
Sabin, F. R. (1923). Johns Hopk. Hosp. Bull., 34, 277.

Sturgis, C. C and Bethell, F. H. (1943). Physiol. Rev., 23, 279.

Tötterman, G. (1948). Acta med. scand., 130, 176.

Turchini, J. and Kien, L. K. van. (1955). Rev. belge. Path., 24, 520.

Weiner, H. A. and Morkovin, D. (1952). Amer. J. Med., 13, 58.

Whitby, L. E. H. and Britton, C. J. C.(1953). Disorders of the Blood, 7 th ed. London.

Wintrobe, M. M.(1951). Clinical Hematology, 3rd ed. London. Wolman, I. J. (1951). Quart. Rev. Pediat., 6, 287. 